\title{
Influence of Nanofillers on Electrical Characteristics of Epoxy Resins Insulation
}

\author{
Qi Wang and George Chen \\ School of Electronics and Computer Science \\ University of Southampton \\ Southampton, United Kingdom \\ qw08r@ecs.soton.ac.uk
}

\author{
Abdulsalam S. Alghamdi \\ Electrical and Computer Engineering Department \\ King Abdulaziz University \\ Kingdom of Saudi Arabia \\ asgalhamdi@kau.edu.sa
}

\begin{abstract}
Epoxy resin is widely used in high voltage apparatus as insulation. Fillers are often added to epoxy resin to enhance its mechanical, thermal and chemical properties. The addition of fillers can deteriorate electrical performance. With the new development in nanotechnology, it has been widely anticipated that the combination of nanoparticles with traditional resin systems may create nanocomposite materials with enhanced electrical, thermal and mechanical properties. In the present paper we have carried out a comparative study on dielectric properties and space charge behaviour of epoxy resin/nanocomposites with nano-fillers of $\mathrm{SiO}_{2}$ and $\mathrm{Al}_{2} \mathrm{O}_{3}$. The epoxy resin (LY556), commonly used in power apparatus, was used to investigate the dielectric behaviour of epoxy resin/nanocomposites with different filler concentrations. The epoxy resin/nanocomposite thin film samples were prepared and tests were carried out to measure their dielectric permittivity and tan delta value in frequency range of $1 \mathrm{~Hz}-1 \mathrm{MHz}$. The space charge behaviours were also observed by using the pulse electroacoustic (PEA) technique. In addition, traditional epoxy resin/microcomposites were also prepared and tested and the test results were compared with those obtained from epoxy resin/nanocomposites.
\end{abstract}

Keywords-nanocomposites, epoxy resin, nanofillers, dielectric properties, space charge.

\section{INTRODUCTION}

Epoxy resin is one of the most commonly used thermosetting materials in high voltage apparatus as insulation due to its excellent mechanical, electrical properties and chemical stability. In recent years, the nano reinforced epoxy resin has attracted a wide interest as it enhances the epoxy's properties significantly. Researches on nano reinforced epoxy resin composites have been carried out ceaselessly. The recent investigation has shown that the epoxy/nanocomposites demonstrate some advantages in both mechanical and dielectric properties $[1,2]$ comparing with pure resin system and epoxy with micrometer-size fillers. One of the interesting observations was that over a wide range of frequencies, the dielectric permittivity values in epoxy nanocomposites are normally lower than both base resin and epoxy with micrometer-size fillers at lower concentrations (depend on filler type and size) [1]. For both $\mathrm{TiO}_{2}$ and $\mathrm{ZnO}$ nano fillers, as the loading filler concentration increases, the permittivity of epoxy nanocomposites increases as well [2]. Earlier researches also showed that the presence of nano fillers in epoxy resin affects the space charges accumulation in epoxy resin. Epoxy nanocomposites seem to accumulate less charge compared with filler-free epoxy resin [3]. It was also observed that epoxy nanocomposites have faster charge dynamics, especially for negative charges [4].

The purpose of the present paper is to study the effects of nano-size fillers on space charge behaviors and dielectric permittivity of epoxy/nanocomposites. It aims to investigate the effects of the filler type, concentration and size on epoxy/nanocomposites' dielectric properties. Both $\mathrm{SiO}_{2}$ and $\mathrm{Al}_{2} \mathrm{O}_{3}$ nano fillers are used in this study. The permittivity of epoxy/nanocomposites with different concentrations is measured and the pulsed electroacoustic technique is used to monitor space charge behaviors of the samples.

\section{EXPERMENTAL DETAILS}

\section{A. Materials}

The material used in this study to produce epoxy resin specimen was Araldite LY556 (Bisphenol-A type) and the hardener HY917 (anhydride type hardener), supplied by Huntsman. The epoxy resin system is widely used in practice and has an advantage of low viscosity at room temperature. Both nanoparticles of silicon dioxide (average diameter $25 \mathrm{~nm}$ ) and aluminium oxide (diameter 30-40nm) supplied by NanoAmor were used as fillers. Micro-sized $\mathrm{SiO}_{2}$ fillers supplied by Huntsman were also used to show how filler size influence the dielectric properties of epoxy resin.

\section{B. Process}

The mould used to produce epoxy/nanocomposites consists of two metal plates, with a polymer film spacer in the middle. The thickness of epoxy specimens is controlled by the thickness of the spacer. For this study the thickness of spacer used is $200 \mu \mathrm{m}$. The plate surface was polished to achieve even and smooth sample surfaces. To help release the specimen from the mould after curing, both the plate surface was smeared with a very thin layer of silicon grease.

The suggested mix ratio of araldite and hardener 1: 0.9 (by weight), and the concentration of accelerator is 1 parts in per 100 parts epoxy resin. The epoxy resin specimens $(200 \mu \mathrm{m})$ with loading concentrations of nano-fillers (both $\mathrm{SiO}_{2}$ and 
$\left.\mathrm{Al}_{2} \mathrm{O}_{3}\right) \quad 0.1 w t \%, 0.3 w t \%, 0.5 w t \%, \quad 1 w t \%, 3 w t \%$ and $5 w t \%$ were produced. Pure epoxy resin specimens and specimens with micro-size $\mathrm{SiO}_{2}$ fillers were also prepared for comparison purpose. Before the process of preparing epoxy resin specimen, epoxide needs to be pre-heated to $40^{\circ} \mathrm{C}$ in an oven to reduce its viscosity. Then both epoxy resin and hardener were taken into beakers separately. To remove the gas bubbles, both of them need to be degassed in a vacuum oven for $1 \mathrm{~h}$ at $40^{\circ} \mathrm{C}$ before mixing. After the completion of degas process, the fillers (micro and nano) were dispersed into epoxy resin slowly with hand stirring. The hardener was added into the resulting epoxy/nano-filler solutions and then the mixture was stirred with both high speed mechanical mixer (at 600 $\mathrm{rpm}$ ) and ultrasonic liquid processor for $1 \mathrm{~h}$ each. The mixture was degassed in the vacuum oven for another 20 min at $40^{\circ} \mathrm{C}$ to remove gas bubbles generated during the mixing process. After degassing, the mixture was poured into the mould. Then the mould was placed into the oven at $80^{\circ} \mathrm{C}$ to cure for $4 \mathrm{~h}$ followed by $4 \mathrm{~h}$ post-cure at $120^{\circ} \mathrm{C}$. Finally removing the cured resin from the mould, the $200 \mu \mathrm{m}$ specimen was ready for testing.

Scanning electron microscope (SEM) was used to exam to dispersion of nano-size filler in the epoxy/nanocomposites. The even dispersion of nano-size filler in the resin can be seen from Fig. 1. Therefore it is confirmed that the filler dispersed uniformly in the result specimens.

\section{RESULTS AND DISCUSSIONS}

\section{A. Dielectric Spectroscopy Measurement}

The dielectric permittivity of epoxy/nanocomposites was measured over a wide range of frequency using dielectric spectroscopy (Solatron 1260). During all the measurements, the temperature was maintained at room temperature. Thus the influence of temperature on results can be ignored.

For both epoxy/nanocomposites with $\mathrm{SiO}_{2}$ and $\mathrm{Al}_{2} \mathrm{O}_{3}$ nano fillers and with different concentrations, the variations of dielectric permittivity as a function of frequency are shown in Fig. 2.

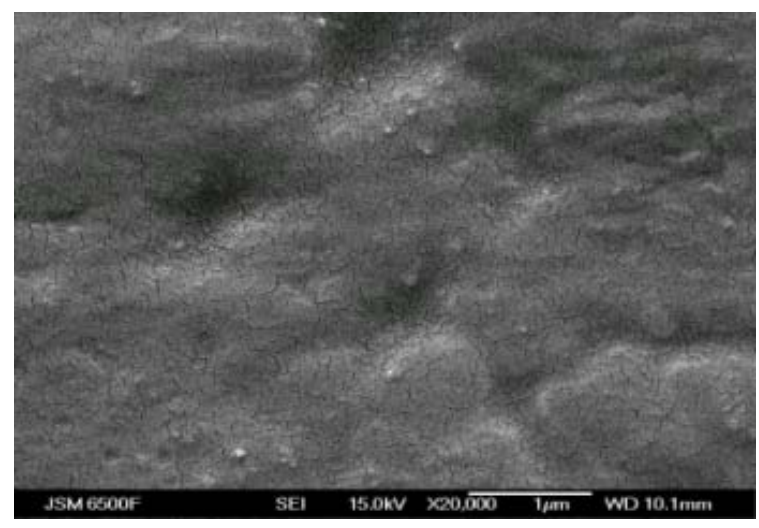

Figure 1. SEM Image of the Epoxy- $\mathrm{SiO}_{2}$ Nanocomposite
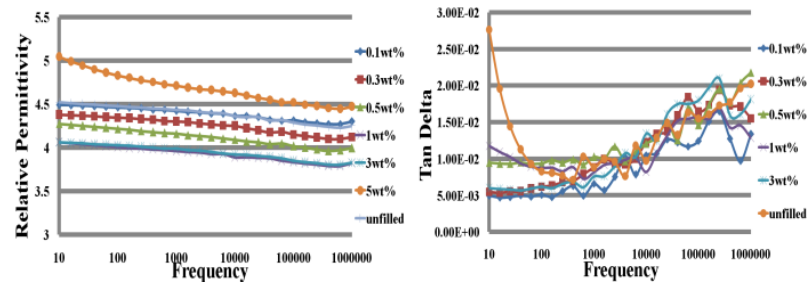

(a) Epoxy-SiO2 nanocomposites
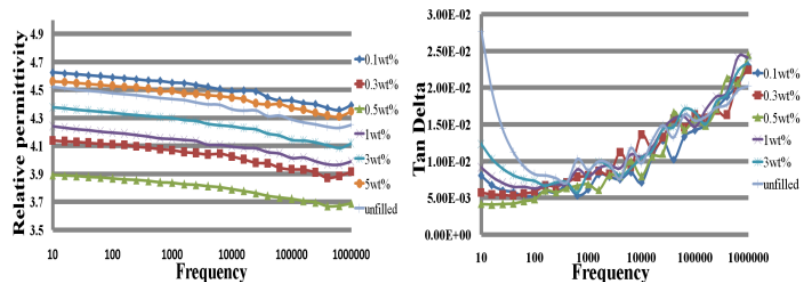

(b) Epoxy-A12O3 nanocomposites

Figure 2. Variations of permittivity and Tan Delta with respect to frequency

In the present case, the effective permittivity of the epoxy/nanocomposites is governed by the polarization associated with epoxy and nano $\mathrm{SiO}_{2} / \mathrm{Al}_{2} \mathrm{O}_{3}$ particles, as well as the interfacial polarization at the interface between epoxy and nano particles. It is also well known that the frequency of the measurements will influence the polarization process. Thus as expected, it can be seen from Fig. 2, both epoxy$\mathrm{SiO}_{2} / \mathrm{Al}_{2} \mathrm{O}_{3}$ nanocomposites and unfilled epoxy show a decrease in effective permittivity with increasing frequency. In a typical epoxy resin system, the permittivity of epoxy is determined by the number of orientable dipoles present in the system and their ability to orient under an applied electric field $[5,6]$. As in the epoxy chain, most of the free dipolar functional groups are able to orient under lower frequency of applied field. Thus the epoxy composites tend to have higher permittivity in lower frequency range. When the frequency of the applied voltage increases, it will become more difficult for larger dipolar groups to orient themselves. Thus the effect of dipolar groups on the permittivity is reducing continuously as the frequency increasing. Moreover, the increasing of frequency of the applied filed will also result in reducing of $\mathrm{SiO}_{2} / \mathrm{Al}_{2} \mathrm{O}_{3}$ fillers' inherent permittivity [7]. The combination of both effect results in the reduction of epoxy/nanocomposites' permittivity with increasing frequency.

There is another interesting observation from both Fig.2 (a) and Fig. 2 (b). For both epoxy- $\mathrm{SiO}_{2} / \mathrm{Al}_{2} \mathrm{O}_{3}$ nanocomposites, the permittivities of the composites with $0.1 \%$ nano filler loading are similar to the unfilled epoxy. It also can be seen from Fig. 2 (a), the permittivity for epoxy- $\mathrm{SiO}_{2}$ nanocomposites decrease as the filler concentration increases, and the relative permittivity reaches its lowest value when the loading concentration is between $1 \%$ and $3 \%$. Then the permittivity of epoxy- $\mathrm{SiO}_{2}$ nanocomposites begins to increase as filler concentration increases further more. Fig. 2 (b) shows a similar observation on epoxy- $\mathrm{Al}_{2} \mathrm{O}_{3}$ nanocomposites, with 
the lowest permittivity occurs between $0.5 \%$ and $1 \%$. This observation is surprising as most of the earlier investigations showed that lower loading concentration (even much less than $1 \%$ ) of nano-size fillers will lead to lower permittivity [2]. Earlier study also stated that the permittivity of epoxy/nanocomposites increases with increasing nano filler concentration in epoxy. However, there are also similar observations in the literature where the nanocomposites' permittivity drops at lower concentration and then increases again as the filler concentration increases to a high value (more than $0.5 \%$ ) [8]. Reduction of effective permittivity with increasing nano $\mathrm{SiO}_{2}$ filler concentration may be caused by the following reason. The interaction between nano $\mathrm{SiO}_{2}$ filler and epoxy chain reduces the mobility of epoxy chain in the bulk material, which will result in decreasing of the effective permittivity of epoxy/nanocomposites. When a small amount of nano filler is loading into epoxy, due to the interaction between filler and epoxy chain, the thin immobile nano layers can be formed. Those thin immobile nano layers will restrict the mobility of the epoxy chain [9]. As the loading concentration increases, more immobile nano layer formed and the mobility of epoxy chain decreased continuously, resulting in reducing of nanocomposites' permittivity. Moreover, the influence of the filler's inherent permittivity on resulting nanocomposites' permittivity increase as the loading concentration increases. The permittivity of two phase dielectric satisfys the Lichtenecker-Rother mixing rule (1):

$$
\log \varepsilon_{\mathrm{c}}=\mathrm{x} \log \varepsilon_{1}+\mathrm{y} \log \varepsilon_{2}
$$

where, $\varepsilon_{\mathrm{c}}$ is the resultant composite permittivity, $\varepsilon_{1}$ and $\varepsilon_{2}$ are the permittivity of filler and epoxy and $\mathrm{x}, \mathrm{y}$ are concentrations of filler and polymer.

It can be obtained from the rule that the influence of filler permittivity on nanocomposites increases as the filler concentration increases. Thus as nano $\mathrm{SiO}_{2}$ filler has a lower permittivity compared with unfilled epoxy, the increasing concentration of the filler will result in reducing of nanocomposites' permittivity. Fig. 2 (b) also gives similar observations. It also needs to be noticed that epoxy- $\mathrm{Al}_{2} \mathrm{O}_{3}$ nanocomposites have higher permittivity compared with nanocomposites with nano $\mathrm{SiO}_{2}$ fillers. This is because nano $\mathrm{Al}_{2} \mathrm{O}_{3}$ particles have a high permittivity than nano $\mathrm{SiO}_{2}$ particles. So the type of nano fillers also has a significant influence on nanocomposites' permittivity.

The variation of tan delta value in both epoxy- $\mathrm{SiO}_{2} / \mathrm{Al}_{2} \mathrm{O}_{3}$ composites are also presented in Fig. 2. The tan delta value in both epoxy- $\mathrm{SiO}_{2} / \mathrm{Al}_{2} \mathrm{O}_{3}$ nanocomposites decrease at lower frequencies (less than $100 \mathrm{~Hz}$ ). It can also be obtained from Fig.2 that the tan delta value of unfilled epoxy is higher than epoxy- $\mathrm{SiO}_{2} / \mathrm{Al}_{2} \mathrm{O}_{3}$ nanocomposites in this frequency range. However, when the applied frequency is higher than $100 \mathrm{~Hz}$, there is a continuous increase in tan delta value in both epoxy$\mathrm{SiO}_{2} / \mathrm{Al}_{2} \mathrm{O}_{3}$ nanocomposites with increasing frequency. Moreover, there is no significantly difference in tan delta value between unfilled epoxy and both epoxy- $\mathrm{SiO}_{2} / \mathrm{Al}_{2} \mathrm{O}_{3}$ nanocomposites.

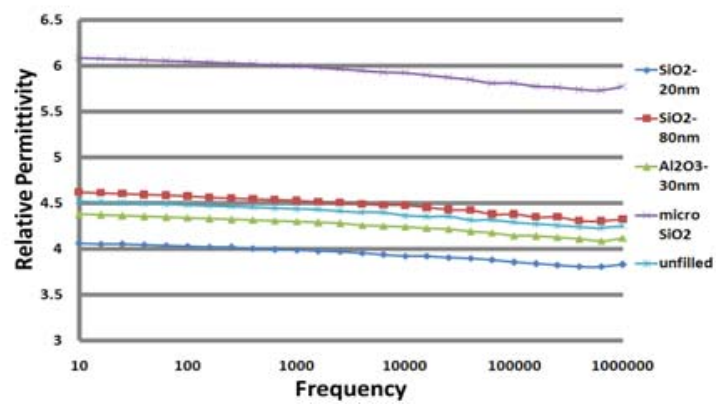

Figure 3. Variations of permittivity with respect to filler size

The influence of filler size on epoxy/nanocomposites' permittivity can be seen from Fig. 3. The composite with micro-size filler seems to have a higher permittivity than the nanocomposites. This is probably due to immobility of epoxy chain in nanocomposites due to a strong interaction at the interface.

\section{B. Space Charge Measurement}

The Pulsed electro-acoustic (PEA) system was used for measuring the space charge accumulation in epoxy nanocomposites. A voltage of $6 \mathrm{kV}$ had been applied to specimens with approximately $0.2 \mathrm{~mm}$ thickness (The applied field is $30 \mathrm{kv} / \mathrm{mm}$ ) at room temperature (approximately $20^{\circ} \mathrm{C}$ ) for 90 minutes. In the present case, the results from "volts-off" measurements were used to investigate the charge accumulation in the specimens. The "volt-off" measurement measures charge formation immediately after the applied voltage has been removed.

The "volts-off" space charge accumulation of specimens with different nano $\mathrm{SiO}_{2}$ filler concentrations is shown in Fig. 4. It can be seen from Fig. 4 (a), a large amount of homocharges is observed adjacent to both electrodes for unfilled epoxy. As the duration of the applied voltage increases, the amount of charge in the specimen increases as well. Charges are dictated by homocharges, which means that the charge injection takes

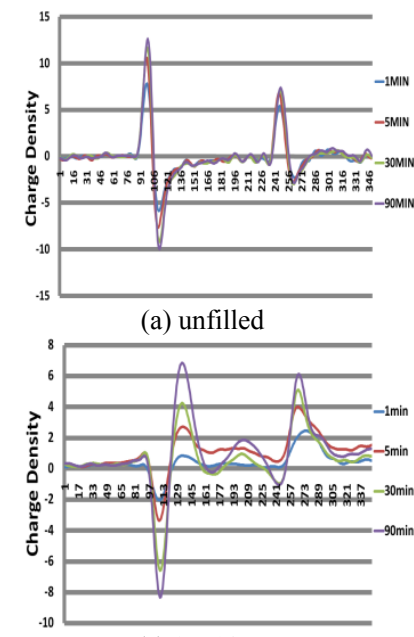

(c) $3 \mathrm{wt} \%$

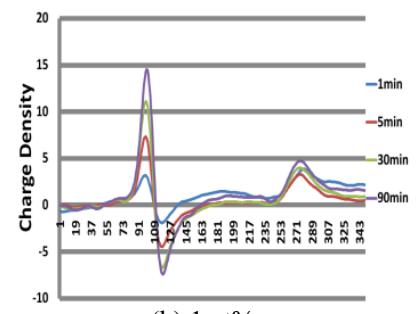

(b) $1 \mathrm{wt} \%$

(d) $5 \mathrm{wt} \%$

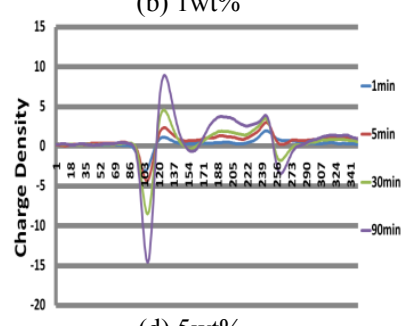


Figure 4. Charge build-up in epoxy- $\mathrm{SiO}_{2}$ nanocomposites at $6 \mathrm{KV}$

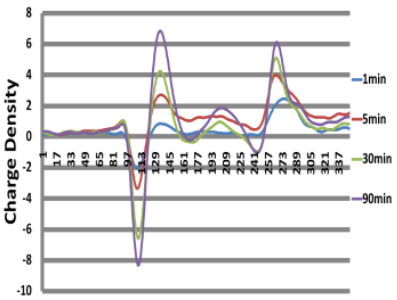

(a) $\mathrm{SiO}_{2}$

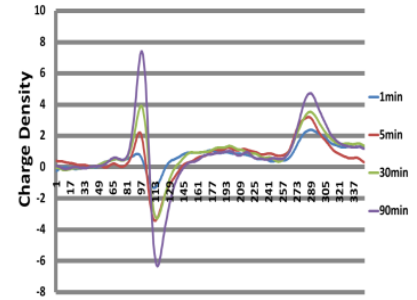

(b) $\mathrm{Al}_{2} \mathrm{O}_{3}$
Figure 5. Charge build -up in $3 \mathrm{wt} \%$ epoxy- $-\mathrm{SiO}_{2} / \mathrm{Al}_{2} \mathrm{O}_{3}$ nanocomposites

place from both electrodes. The heterocharges which is caused by ionization process may also present in the specimen. However, as the PEA system only measures the net charges, so it might be covered by the charge injection. Compared with the unfilled samples, Fig. 4 (b) shows a similar charge distribution in specimen with $1 \%$ nano $\mathrm{SiO}_{2}$ filler. However, It is noticed that $1 \%$ nanocomposite has a slower initial charge build-up rate. The magnitude of charges in $1 \%$ samples is slightly less than that in the unfilled one. The reason for such decreasing in the magnitude of space charge is either the presence of nano filler has hindered the charge injection or more heterocharges are generated due to the ioniszation process. As the presence of the nano $\mathrm{SiO}_{2}$ fillers, the heterocharges generated by ionization process should increase. Thus more heterocharges accumulated closed to the electrodes. The small amount of heterocharges will cancel out with some of the injected charges. Therefore the net charges observation from the PEA system shows a small decrease in the magnitude of space charges. As shown in Fig. 4 (c), when the filler concentration increases to $5 \%$, space charge distribution is very different. There is a positive peak close to the cathode as a result of heterocharges accumulation. Thus it is believed that the increasing concentration of nano filler will result in more heterocharges formation. When the more the fillers are added into the epoxy sample, the more heterocharges are accumulated adjacent to the cathode as shown in Fig. 4 (d).

Fig. 5 shows the observation of space charge accumulation in both epoxy- $\mathrm{SiO}_{2} / \mathrm{Al}_{2} \mathrm{O}_{3}$ nanocomposites with $3 \%$ filler concentrations. It can be seen clearly that charges are dictated by homocharges in epoxy- $\mathrm{Al}_{2} \mathrm{O}_{3}$ nanocomposites, whereas in epoxy- $\mathrm{SiO}_{2}$ composites, charges are dominated by heterocharges. But there is a small amount of positive charge presence in the middle of both samples. The difference in charge formation between two nanocompostes is caused by the amount of heterocharges accumulated adjacent to the electrodes. Thus compared with $\mathrm{Al}_{2} \mathrm{O}_{3}$ particles, the same amount of $\mathrm{SiO}_{2}$ particles seems to have a better enhancement on the ionization process in nanocomposites.

\section{CONCLUSION}

Both the dielectric permittivity and space charge accumulation in epoxy nanocomposites loaded with different concentration of nano size $\mathrm{SiO}_{2}$ and $\mathrm{Al}_{2} \mathrm{O}_{3}$ fillers have been investigated using dielectric spectroscopy and the PEA method. The following conclusion may be drawn based on this study.

The permittivity for both epoxy- $\mathrm{SiO}_{2} / \mathrm{Al}_{2} \mathrm{O}_{3}$ nanocomposites decreases at lower concentration (less than $1 \%$ ). The relative permittivity of nanocomposites appears to have a minimum value with a threshold filler concentration ( $1 \mathrm{wt} \%$ for nano $\mathrm{SiO}_{2}$ and $0.5 \mathrm{wt} \%$ for nano $\mathrm{Al}_{2} \mathrm{O}_{3}$ ). When the filler content is above the threshold value, the permittivity of nanocompsoites begins to increase with filler concentration. The epoxy- $\mathrm{Al}_{2} \mathrm{O}_{3}$ nanocomposite has a higher permittivity than epoxy- $\mathrm{SiO}_{2}$ nanocomposites as the $\mathrm{Al}_{2} \mathrm{O}_{3}$ particles have a higher inherent permittivity. Moreover, the increase in filler size will lead to a larger permittivity as well.

The presence of nano particles seems to enhance the ionization process inside the sample, especially at higher filler concentrations. The filler type also has a significant influence on space charge accumulations. It can also be observed that higher content of nano size filler $\left(5 \mathrm{wt} \%\right.$ for $\left.\mathrm{SiO}_{2}\right)$ will lead to more complicated charge accumulation.

\section{REFERENCES}

[1] Tanaka, T.; , "Dielectric nanocomposites with insulating properties," Dielectrics and Electrical Insulation, IEEE Transactions on , vol.12, no.5, pp. 914- 928, Oct. 2005.

[2] Singha, S.; Thomas, M.J.; , "Dielectric properties of epoxy nanocomposites," Dielectrics and Electrical Insulation, IEEE Transactions on, vol.15, no.1, pp.12-23, February 2008.

[3] Castellon, J.; Agnel, S.; Toureille, A.; Frechette, M.; , "Space Charge Characterization of multi-stressed microcomposite nano-filled epoxy for Electrotechnical Applications," Electrical Insulation and Dielectric Phenomena, 2008. CEIDP 2008. Annual Report Conference on , vol., no., pp.532-535, 26-29 Oct. 2008.

[4] Fabiani, D.; Montanari, G.C.; Dardano, A.; Guastavino, G.; Testa, L.; Sangermano, M.; , "Space Charge Dynamics in Nanostructured Epoxy Resin," Electrical Insulation and Dielectric Phenomena, 2008. CEIDP 2008. Annual Report Conference on , vol., no., pp.710-713, 26-29 Oct. 2008.

[5] J. P. Eloundou, "Dipolar relaxations in an epoxy-amine system", European Polymer J., Vol. 38, pp. 431-438, 2002.

[6] L. D. Zhang, H. F. Zhang, G. Z. Wang, C. M. Mo and Y. Zhang, "Dielectric behavior of nano-TiO2 bulks", Phys. Stat. Sol., Vol. 157, pp. 483-491, 1996.

[7] J. K. Nelson and J. C. Fothergill, "Internal Charge Behavior of Nanocomposites”, Nanotechnology, Vol. 15, pp. 586-595, 2004.

[8] Huicheng Shi; Naikui Gao; Haiyun Jin; Gang Zhang; Zongren Peng; , "Investigation of the effects of nano-filler on dielectric properties of epoxy based composites," Properties and Applications of Dielectric Materials, 2009. ICPADM 2009. IEEE 9th International Conference on the , vol., no., pp.804-807, 19-23 July 2009.

[9] G. Tsagaropoulos and A. Eisenberg, "Dynamic Mechanical Study of the Factors Affecting the Two Glass Transition Behavior of Filled Polymers Similarities and Differences with Random Ionomers", Macromolecules, vol. 28, pp. 6067-6077, 1995. 